\title{
ORIGINAL
}

\section{Geranylgeranylacetone prevents stress-induced decline of leptin secretion in mice}

\author{
Miki Itai, Yuki Kuwano, Tatsuya Nishikawa, Kazuhito Rokutan, and Kensei Nishida \\ Department of Pathophysiology, Institute of Biomedical Sciences, Tokushima University Graduate School
}

\begin{abstract}
Geranylgeranylacetone (GGA) is a chaperon inducer that protects various types of cell and tissue against stress. We examined whether GGA modulated energy intake and expenditure under stressful conditions. After mice were untreated or treated orally with GGA (0.16 g per $\mathrm{kg}$ body weight per day) for $10 \mathrm{days,}$ they were subjected to 2 -h restraint stress once or once a day for 5 consecutive days. GGA administration did not affect corticosterone response to the stress. Restraint stress rapidly decreased plasma leptin levels in control mice. GGA significantly increased circulating leptin levels without changing food intake and prevented the stress induced decline of circulating leptin. However GGA-treated mice significantly reduced food intake during the repeated stress, compared with control mice. GGA prevented the stress-induced decline of leptin mRNA and its protein levels in epidydimal adipose tissues. We also found that GGA decreased ghrelin mRNA expression in gastric mucosa before the stress, whereas GGA-treated mice recovered the ghrelin mRNA expression to the baseline level after the repeated stress. Leptin and ghrelin are now recognized as regulators of anxiety and depressive mood. Our results suggest that GGA may regulate food intake and relief stress-induced mood disturbance through regulating leptin and ghrelin secretions. J. Med. Invest. 65 : 103 - 109, February, 2018
\end{abstract}

Keywords : geranylgeranylacetone, stress, food intake, leptin, ghrelin

\section{INTRODUCTION}

Leptin is a $16-\mathrm{kDa}$ protein identified as the obese gene product that plays a crucial role in body weight regulation (1). Leptin is synthesized and secreted mainly by white adipose tissues, and its plasma concentrations are proportional to adiposity in humans. Leptin is also expressed in other organs including placenta, ovaries, skeletal muscle, stomach, mammary epithelial cells, bone marrow, pituitary gland, liver and the brain (2). Leptin controls various aspects of energy intake and expenditure by inhibiting appetite, suppressing lipogenesis, modulating T-cell activity and the ovulatory cycle, promoting angiogenesis and surfactant expression in type II pneumocytes, regulating bone metabolism and inflammatory responses, and influencing the stress response $(3,4)$. As to the effect of leptin on the stress response, its relationship with the hypothalamo-pituitary-adrenal (HPA) axis and feeding has been investigated into appreciable detail in experimental animals. The complex action of leptin on the HPA axis in relation to both stress adaptation and feeding may hold for vertebrates in general (5). Leptin produced in the brain and particularly in the hypothalamus/ the arcuate can act on the paraventricular nuclei (PVN) to affect the HPA-axis activity. Peripheral infusion of leptin before and during restraint stress suppresses stress-induced corticosterone release in rats (6). Injected leptin inhibits stress-induced anorexia and behavioral deficits in rats (6). Thus, leptin is now considered to be a stress-related hormone (7). However, its effects on the HPA axis likely depends on the strength and the type of stressors.

The heat-shock proteins (HSPs) have a cytoprotective property as intracellular chaperons, by which aberrantly folded or damaged

Received for publication January 10, 2018 ; accepted January 19, 2018.

Address correspondence and reprint requests to Kensei Nishida, MD, $\mathrm{PhD}$, Department of Pathophysiology, Institute of Biomedical Sciences, Tokushima University Graduate School, 3-18-15 Kuramoto-cho, Tokushima 770-8503, Japan and Fax : +81-88-633-9008. proteins in various stressful conditions are repaired and, if necessary, degraded for cellular homeostasis $(8,9)$. A wide variety of stresses, such as ischemia and inflammation, induce an increase in the expression of HSPs, and particularly a stress-inducible HSP70 has been proved to exhibit a cytoprotective function both in vitro and in vivo (10). Geranylgeranylacetone (GGA) is an acyclic isoprenoid compound, which has been widely used as an anti-ulcer agent without any serious adverse effects (11). GGA is known as a non-toxic chaperone inducer that specifically induces HSPs, especially HSP70 in various tissues, including gastric mucosa (10), liver (12), and the brain (13). Recent studies have also implicated that GGA-mediated HSP105 induction may provide a novel therapeutic strategy for depression-like behavior (14). These reports suggest that administration of GGA may have a protective effect against several injury models and human diseases. There is one report showing the effect of GGA on leptin secretion. Long-term treatment of GGA decreases body weight gain and serum leptin levels in high-fat feeding mice (15). However, it has not been examined whether GGA could modulate leptin secretion under stressful conditions.

Here, we examined whether oral GGA administration modulated the production of leptin in epididymal adipose tissue and ghrelin in gastric mucosa using a restraint stress model of mice.

\section{MATERIALS AND METHODS}

Animals

Male wild-type C57BL/6J mice were purchased from Charles River Laboratories (Kanagawa, Japan). All mice were treated in accordance with the National Institute of Health Guide for the Care and Use of Laboratory Animals, and all procedures were approved by the Animal Care Committee of Tokushima University Graduate School. Mice were bred and maintained under specific pathogenfree conditions (SPF) at constant temperature of $23 \pm 2^{\circ} \mathrm{C}$ and $65 \%$ 
humidity on a 12 -h dark-light cycle (lights on at $08: 30$ ). All mice were free to access a standard rodent chow (Oriental Yeast, Tokyo, Japan). Body weights and food intakes of mice were measured at $10: 00$ every three days before starting the experimental manipulations.

\section{GGA treatment and restraint stress}

At 8 or 9 weeks of age, male mice were taken a standard rodent chow powder (control diet ; Oriental Yeast) or the powder supplemented with GGA granule (provided by Eisai Co. Tokyo Japan). GGA granules were mixed with the chow powder at a concentration of $0.5 \%$. Mice at 8 or 9 weeks of age (average weight of $24 \mathrm{~g}$ ) consumed $4.22 \mathrm{~g}$ of the chow per day. The actual average intake of GGA was calculated to be $0.16 \mathrm{~g}$ per $\mathrm{kg}$ body weight per day. This dose was shown to induce HSP70 in mouse gastric mucosa (16).

After mice took GGA-supplemented chow or control chow for 10 days, they were exposed or left unexposed to restraint stress. Restraint stress was done by placing mice in a restrainer (a rounded plastic tube $27 \mathrm{~mm}$ in diameter) for $2 \mathrm{~h}$ one time or once a day for 5 consecutive days. During the restraint stress, mice continued to take GGA-supplemented or control chow powders and their body weights and food intakes were measured daily at $10: 00$ prior to the stress. Before and immediately after a single or 5-time restraint stress, mice were sacrificed under deep anesthesia with diethyl ether. Blood was collected by cardiac puncture. At the same time, epididymal adipose tissue and stomach were also collected from the mice. After washing with cold saline, gastric mucosa was removed by a slide glass. Removed epididymal adipose tissue and gastric mucosa were stored at $-80^{\circ} \mathrm{C}$ until analysis. For mRNA measurements, epididymal adipose tissue and gastric mucosa were immediately incubated with the RNA later stabilization reagent (Ambion, Austin, TX) for $24 \mathrm{~h}$ and then stored at $-80^{\circ} \mathrm{C}$ until analysis.

\section{Quantitative real-time reverse transcription (RT)-PCR}

Total RNA was extracted from the stored epididymal adipose tissue and gastric mucosa using RNAiso Plus reagent (Takara, Otsu, Japan). Contaminating DNA was removed with deoxyribonuclease using the TURBO DNA-free ${ }^{\mathrm{TM}}$ kit (Ambion). Complementary DNA was prepared from total RNA $(2 \mu \mathrm{g})$ of epididymal adipose tissue and gastric mucosa using oligo dT and random primer using the ReverTra Ace (Toyobo, Osaka, Japan). Amounts of leptin and hspal mRNAs in epididymal adipose tissue and ghrelin mRNA in gastric mucosa were measured by real-time reverse transcription (RT)-PCR. Glyceraldehyde 3-phosphate dehydrogenase (gapdh) mRNA was used as an endogenous quantitative control. The following primer sets were used to amplify leptin mRNA, 5'-CAGGATCAATGACATTTCACACA-3' (forward) and 5'-GCTGGTGAGGACCTGTTGAT -3' (reverse) ; ghrelin mRNA, 5'-AAGAAGCCACCAGC-3' (forward) and 5'-ATCGAAGGGAGCATTGAAC -3' (reverse) ; hspal mRNA, 5'-GTGTGAGAGGGCCAAG-3' (forward) and 5'-ATGCCCTCGAACAGAG-3' (reverse) ; gapdh mRNA, 5'AACTTTGGCATTGTGGAAGGTAAAC-3' (forward) and 5'-GGATGCAGGGATGATGTTCT -3' (reverse). Real-time RT-PCR was performed by the ABI-PRISM 7500 system using the SYBR Green detection assay (Applied Biosystems, Foster City, CA).

\section{Measurements of plasma leptin and corticosterone levels}

Before and immediately after the restraint stress, mice were anesthetized with diethyl ether, and blood was collected in EDTAcontaining tubes. Plasma was separated by centrifugation at 7,500 $\mathrm{g}$ for 5 min at $4^{\circ} \mathrm{C}$ and stored at $-80^{\circ} \mathrm{C}$ until measurements using enzyme-linked immunosorbent assay (ELISA) systems. Plasma leptin and corticosterone levels were analyzed according to the manufacturer's protocols using Quantikine ELISA (R\&D Systems, Minneapolis, MN) and Corticosterone ELISA kit (Enzo Life Sci- ences, Farmingdale, NY), respectively.

\section{Immunoblot analysis}

Epididymal adipose tissues were homogenized in RIPA buffer (Cell Signaling Tech., Danvers, MA) containing a protease and phosphatase inhibitor cocktail (Sigma-Aldrich, St. Louis, MO) and centrifuged at $10,000 \mathrm{~g}$ for $5 \mathrm{~min}$ at $4^{\circ} \mathrm{C}$. The supernatants $(20 \mu \mathrm{g}$ protein) were separated by sodium dodecyl sulfate-polyacrylamide gel electrophoresis in a 15\% polyacrylamide gel and transferred to a polyvinylidene difluoride membrane (BioRad, Hercules, CA). After blocking with 5\% non-fat drymilk (Cell Signaling Tech.), the membranes were incubated overnight at $4^{\circ} \mathrm{C}$ with a rabbit polyclonal anti-leptin antibody (1: 1000 dilution ; GeneTex, Irvine, CA) or a monoclonal antibody for anti-mouse HSP70 (1 : 1000 ; StressMarq, Victoria, Canada) or for anti-mouse beta actin ( 1 : 5000 ; Santa Cruz Biotech., Santa Cruz, CA). After incubated with the corresponding second antibodies, bound antibodies were detected by an enhanced chemiluminescence Western blotting detection system (Amersham Pharmacia, Piscataway, NJ). The intensities of the bound antibodies were quantified by using the Image Studio software (LI-COR, Lincoln, NE).

\section{Statistical Analysis}

All data were presented as the mean \pm SD from at least three independent experiments. Statistical comparisons between different conditions were done by unpaired $t$-test using the GraphPad Prism program (GraphPad Software Inc., San Diego, CA) . $P$ values of less than 0.05 were regarded as statistically significant.

\section{RESULTS}

Effects of GGA and restraint stress on food intakes and body weight changes

Body weights of GGA or control groups were measured at $10: 00$ every three days before restraint stress and every day during the stress, and daily changes are shown in Figure 1a. Averages of daily food intakes of the mice are also shown in Figure 1b. There was no significant change in body weight gain between GGA and control groups before and during the stress (Figure 1a). Exposure to 2-h restraint stress once a day for 5 consecutive days (5-time restraint stress) inhibited body weight gain similarly in both GGA and control groups (Figure 1a). On the other hand, 5-time restraint stress significantly reduced daily food intakes in GGA-treated mice, but not in control mice (Figure 1b). As a result, GGA-treated mice significantly decreased daily food intake compared with control mice during the stress period.

\section{Effects of GGA and restraint stress on plasma corticosterone levels}

To confirm that the restraint stress actually evoked stress responses in the mice and to examine whether GGA modulated the responses, we first measured plasma corticosterone levels before and immediately after a single or 5 -time restraint stress. Figure $2 \mathrm{a}$ shows that either one- or 5 -time restraint stress similarly increased plasma corticosterone levels. GGA administration did not change plasma corticosterone levels before and after the stress. Thus, in our experimental conditions, GGA did not modulate the plasma corticosterone response and did not improve the stress-induced decline of body weights. However, we found that GGA administration significantly reduced food intake during the stressful situation.

\section{Effects of GGA and restraint on plasma leptin levels}

Although it has been consistently demonstrated that GGA exhibits protective actions against cell and tissue injuries in various types of stress models, we were interested in the enhanced 
a

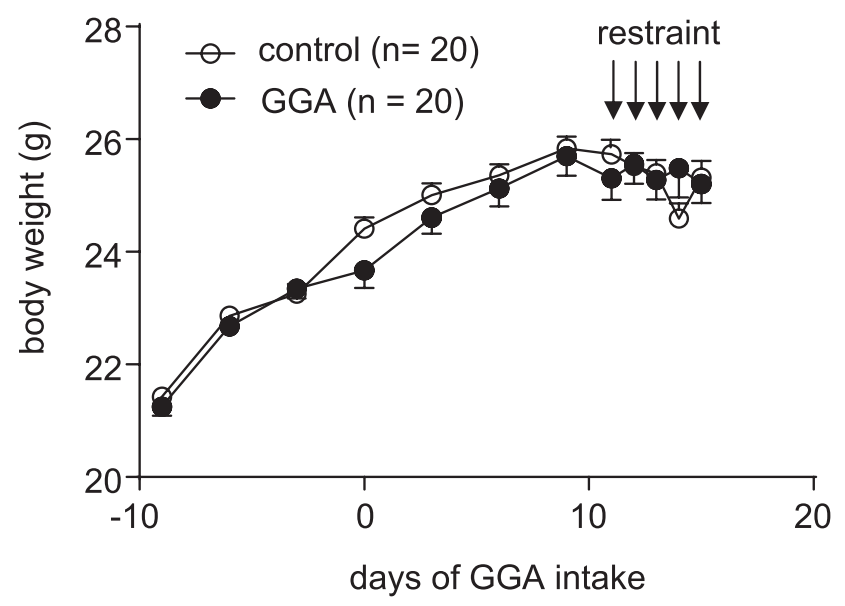

b

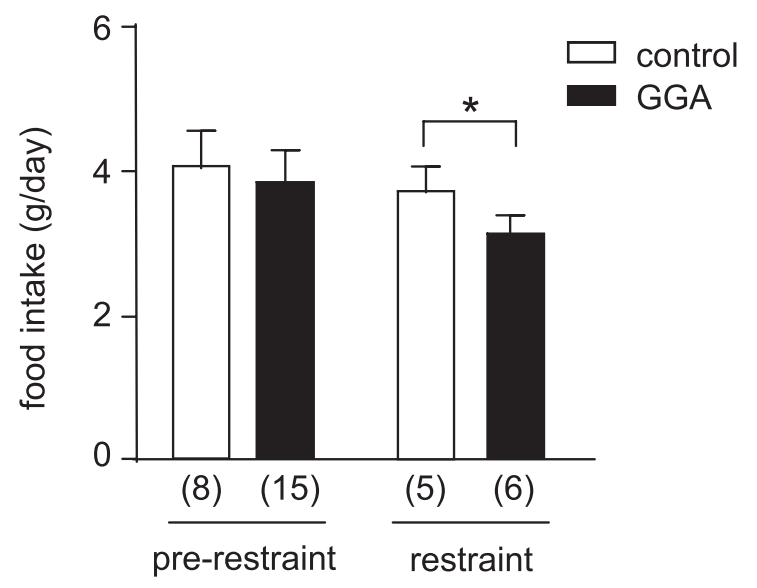

Figure 1. Effects of GGA and restraint stress on daily food intake and body weight changes. (a) Mice were treated with GGA ( $0.16 \mathrm{~g}$ per $\mathrm{kg}$ body weight per day) for 10 days or left untreated (control mice). These mice were exposed to a single 2 -h restraint stress or 2 -h restraint stress once a day for 5 consecutive days (5-time restraint stress). Body weights of GGA-treated or untreated control mice were measured every three days before restraint stress and every day during the stress. Values are means \pm SD $(n=20)$. (b) Food intakes were also measured every three days before restraint stress and every day during the stress. Means \pm SD of daily food intakes are shown. Numbers of mice are indicated in the parentheses. ${ }^{*} P<0.05$ by unpaired $t$-test.

reduction of food intake in GGA group exposed to restraint stress, since we had expected that an anti-stress compound GGA rather improved the stress-induced appetite loss. We therefore tried to reveal the mechanism for this effect.

First we examined the changes in plasma leptin levels. Leptin is known to be one of the potential factors for the regulation of energy intake when exposed to stress (3). As shown in Figure 3a, in control mice, a single restrain stress rapidly decreased plasma leptin concentrations and remained to be low after 5 -time restraint stress. Mice treated with GGA for 10 days significantly increased plasma

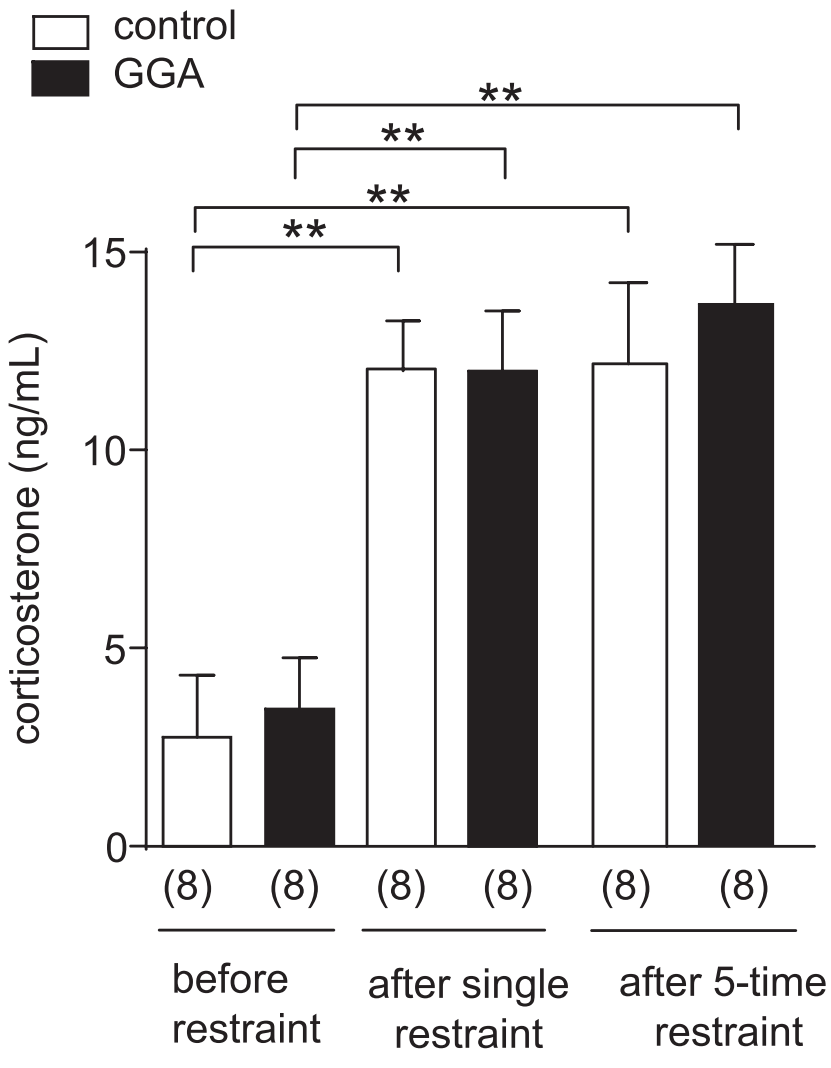

Figure 2. Effects of GGA and restraint stress on plasma corticosterone levels. GGA-treated or untreated control mice were sacrificed under general anesthesia with diethyl ether before the stress at $10: 00$ or immediately after a single or 5 -time restraint stress at $12: 00$. Blood was collected by cardiac puncture. Plasma corticosterone levels were measured using an ELISA kit. Values are means \pm SD. Numbers of mice are indicated in the parentheses. ${ }^{* *} P<0.05$ by unpaired $t$-test.

leptin levels before exposure to restraint stress, compared with control mice (Figure 3a). In addition, a single restraint stress did not significantly decreased plasma leptin levels in GGA-treated mice, and the values were significantly higher than those in control mice (Figure 3a). However, GGA could not prevent the decline of plasma leptin concentrations when restraint stress was repeated for 5 consecutive days (Figure 3a).

Effect of GGA on leptin mRNA and protein expression in epididymal adipose tissues

White adipose tissues are a major source of circulating leptin. We also examined the effect of GGA on leptin by measuring leptin mRNA and protein levels in epididymal adipose tissues. In control mice, a single restraint stress did not change leptin mRNA levels, while the repeated stress for 5 days significantly decreased the mRNA levels (Figure 3b). Daily administration of GGA for 10 days significantly increased expression levels of leptin mRNA before the stress, which was consistent with increased levels of circulating leptin after the GGA administration (Figure 3a). This increase was cancelled after a single restraint stress, and 5-time restraint stress deceased leptin mRNA levels in epididymal adipose tissues, similarly observed in control mice (Figure $3 \mathrm{~b}$ ). When leptin protein levels were compared between GGA-treated and untreated control mice, GGA rather increased leptin in epididymal adipose tissues after a single restraint stress. Consequently, the levels were significantly higher than those of control mice (Figure 3c). 
a

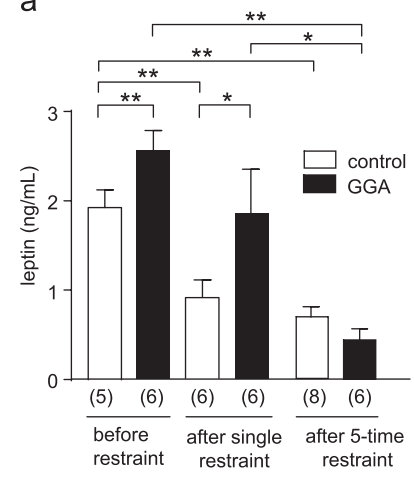

b

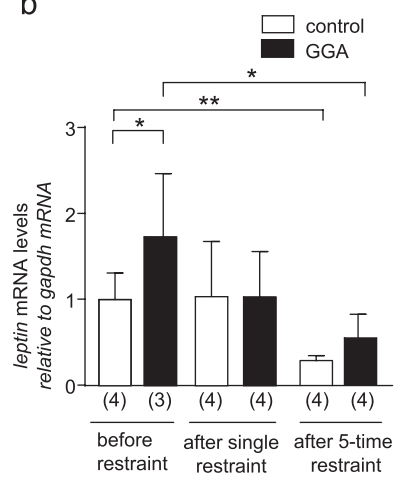

a

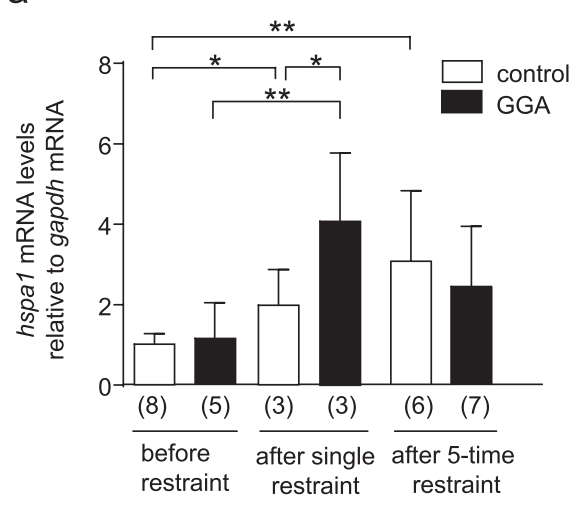

b

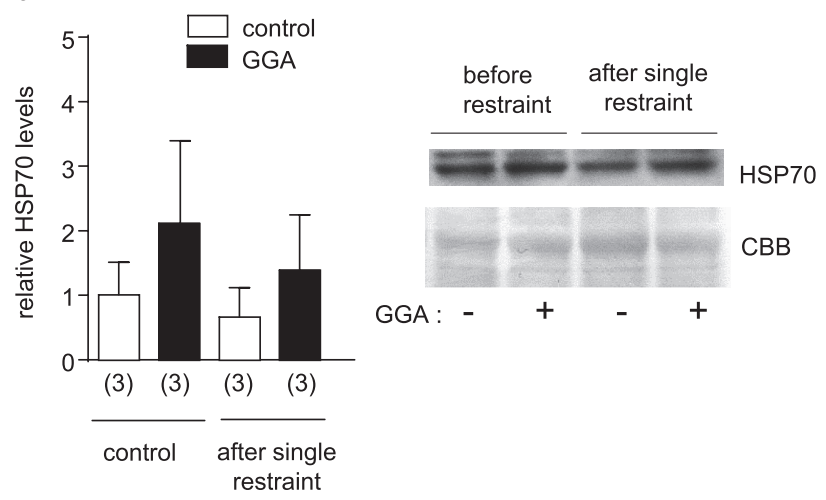

Figure 4. Effects of GGA and restraint stress on hspal mRNA and HSP70 levels in gastric mucosa. (a) Gastric mucosa was prepared from GGA-treated or untreated control mice before or after exposure to a single or 5-time restraint stress. Total RNA was extracted and hspal mRNA levels were assayed by real-time RT-PCR. Gapdh mRNA was used as an endogenous quantitative control. Values are means \pm SD. Numbers of mice assayed are indicated in the parentheses. ${ }^{\star} P<0.05 .{ }^{* *} P<0.01$. (b) Soluble proteins were prepared from gastric mucosa of GGAtreated or untreated control mice before or after exposure to a single restraint stress. HSP70 levels were measured by Western blot analysis using an ant-HSP70 antibody. The levels of HSP70 were standardized using CBB-stained actin band. Values in the left panel are means \pm SD. Numbers of mice assayed are indicated in the parentheses. Representative results are shown in the right panel.

Effects of GGA on HSP70 induction in epididymal adipose tissues

It has been demonstrated that GGA could induce HSP70 in rodent gastric mucosa (10). However, effect of GGA on white adipose tissues has not yet been documented. We examined whether GGA acted on epididymal adipose tissues and induced HSP70. As shown in Figure 4a, a single restraint stress did not significantly stimulate hspal mRNA expression in epididymal adipose tissues of control mice, while 5 -time exposure to restraint stress significantly increased hspal mRNA levels (Figure 4a). GGA treatment alone did not affect hspal mRNA expression, but it significantly augmented $h$ spal mRNA expression after a single restraint stress (Figure 4a). However, protein levels of HSP70 were not significantly increased in GGA-treated mice before and after the restraint stress (Figure $4 \mathrm{~b}$ ).

Thus, GGA treatment appeared to actually act on epididymal adipose tissues and prime them for accelerated hspal mRNA induction under the stressful situation.

\section{Effect of GGA on ghrelin mRNA expression in stomachs}

We also examined the effect of GGA administration on ghrelin production. We could not detect significant amounts of ghrelin in peripheral blood using commercially available ELISA kits. We therefore measured ghrelin mRNA levels in gastric mucosa. As shown in Figure 5, a single or 5-time restraint stress did no change ghrelin mRNA levels in gastric mucosa of control mice. Daily administration of GGA for 10 days significantly reduced ghrelin mRNA levels in gastric mucosa. After 5-time exposure to restraint stress, ghrelin mRNA levels were significantly increased in GGAtreated mice and returned to the baseline level.

\section{DISCUSSION}

We report here that a chaperone inducer GGA may modulate energy intake and expenditure under stressful conditions. GGA activates heat shock factor 1 and exert cytoprotective actions in various organs exposed to ischemia/reperfusion or insults through 


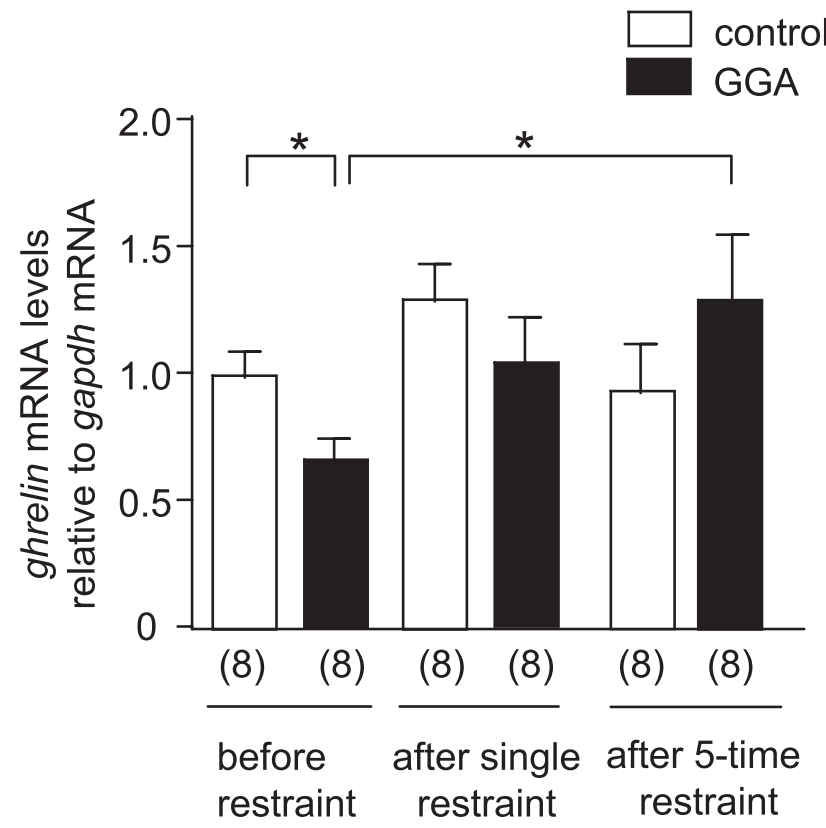

Figure 5. Effects of GGA and restraint stress on ghrelin mRNA levels in gastric mucosa. Gastric mucosa was prepared from GGAtreated or untreated control mice before or after exposure to a single or 5time restraint stress. Total RNA was prepared from gastric mucosa and ghrelin mRNA levels were assayed by real-time RT-PCR. Gapdh mRNA was used as an endogenous quantitative control. Values are means \pm SD. Numbers of mice assayed are indicated in the parentheses. ${ }^{\star} P<0.05$.

induction of HSPs particularly HSP70 (9). At the same time, Adachi et al. reported that GGA improved glucose metabolism and reduced adiposity in an animal model of type 2 diabetes (15). In addition, GGA can pass through blood brain barrier and affect the central nervous system (17). It was showed that orally administered GGA improved not only cognitive function but also reduced the pathological phenotypes in Alzheimer's model mice (17). These results implicated that GGA might improve stress-associated metabolic and mental dysfunctions. We show here for the first time that GGA could act on white adipose tissues and enhance the induction of hspal mRNA when exposed to restrain stress in mice. Moreover, we found that GGA modulated leptin production from the white adipose tissue.

Stress activates multiple neural and endocrine systems to respond to and survive in threatening environments. The corticotropin-releasing factor (CRF) system is a primary initiator of this integrated response, which includes activation of the sympathetic nervous system and the HPA axis. A typical energetic response to an acute stressor is inhibition of food intake, increased heat production, and sustained changes in body weight, behavior, and HPA reactivity, while these responses are varied depending on the nature and severity of the stressor. The effect of chronic psychological stress is more variable. However, few stress experiments focus on energy balance. More information on the phenotype of both humans and animal models during and after exposure to acute or chronic stress is needed to understand mechanisms that control energy intake and body weight under stressful conditions. Central and peripheral injections of CRF $(18,19)$ suppress food intake through peripheral sensory systems independent of direct central modulation of anorexigenic or orexigenic factors. Glucocorticoids also have a potential to modulate food intake. Low doses of glucocorticoid stimulate food intake by facilitating orexigenic activity of neuropeptide Y (NPY) and norepinephrine in the PVN (20). By contrast, high doses of corticosterone suppress food intake, possibly through glucocorticoid-induced insulin release, which inhibits NPY expression (21). In our experimental conditions, we could not detect any difference in circulating corticosterone levels between GGA-treated and untreated control mice before and after exposure to the restraint stress, indicating that GGA did not significantly modulate the reactivity of the HPA axis. We therefore focused on a peripheral anorexigenic (leptin) and orexigenic (ghrelin) factors.

In control mice, a single exposure to 2 -h restraint stress rapidly decreased circulating leptin concentrations without changing its protein and mRNA levels in epididymal adipose tissues. A repetition of the same stress for 5 consecutive days downregulated leptin mRNA expression in the tissues and circulating leptin continued to be low. These results suggest that psychological stress may accelerate consumption of circulating leptin and then down-regulate leptin expression when it was repeated. In our experimental conditions, the repetition of the stress for 5 consecutive days completely blocked daily weight gain without changing daily food intake in control mice. This leptin response may be a compensatory for the stress-induced weight loss. In contrast, daily administration of GGA for 10 days before the stress significantly increased plasma leptin and its mRNA levels in epididymal adipose tissues without changing daily food intake and body weight gain. When GGA-treated mice were exposed to restraint stress, they were resistant to the stress-induced declines of circulating leptin and leptin mRNA expression in epididymal adipose tissues. Although GGA-induced up-regulation of leptin did not significantly reduced food intake before the stress, the maintenance of leptin levels may be associated with an additional decline of food intake, which was observed under repeated restraint stress in GGA-treated mice. On the other hand, there was no difference in daily body weight changes between GGA-treated and control mice in the present experimental conditions.

Leptin plays a central role in controlling appetite and weight in both rodents and humans. This hormone also regulates the four main hypothalamo-pituitary-peripheral axes - adrenal, thyroid, gonadal, and growth hormone axes - at different levels (22). As to the HPA axis, leptin suppresses glucocorticoid secretion during stress-related activation of the adrenal axis. In fact, a systemic injection of leptin produced a significant attenuation in plasma levels of corticosterone in immobilized animals (6). Rats exposed to chronic stress showed decreased basal levels of leptin and systemic administration of leptin can reverse depression-like behaviors in these animals (23). As psychiatric disorders like depression are frequently associated with hypercortisolism, leptin is proposed to exert anti-depressant-like effects due to its inhibition of chronically overactive HPA axis function. The association of low leptin levels and developing depression has been proposed in humans (24). Although there are inconsistent results regarding leptin measurement in major depression $(25,26)$, there seem to be sex differences in plasma leptin measures between depressive patients and healthy controls $(26,27)$. In women, low leptin levels are associated with increased symptoms of depression and there is an inverse relationship between leptin levels and anxiety symptoms independent of body weight (27). Thus, leptin status of depressed patients could serve as a prognostic marker for therapy response. Although the inhibitory effect of leptin on the HPA axis has been suggested to mediate anti-depressant-like effects in animal models. In case of our study, administration of GGA suppressed decline of plasma leptin levels when exposed to the restrain stress, while it could not suppress the elevation of corticosterone.

We also examined changes in circulating ghrelin. Ghrelin is an appetite regulatory hormone mainly produced in the stomach (28). Studies in rodents demonstrated potent stimulatory effects on food intake, increased body weight gain, and increased adiposity with either peripheral or central administration of ghrelin (29-31). The 
orexigenic hypothalamic arcuate neuropeptide (NPY)/Agouti-related peptide-expressing neurons are a prominent direct target of ghrelin action (32). Plasma ghrelin is negatively correlated in the short term with feeding status and in the long term with body mass index (33). Ghrelin also acts in a protective manner to counter anxiety and depression during stressful conditions. Administered ghrelin induces both antidepressant-like and anxiolytic-like behaviors in mice. Moreover, different forms of psychosocial stress lead to plasma ghrelin elevation in rodents and humans $(34,35)$, suggesting its role as a mediator of stress-based eating behaviors $(34,36)$. An activated ghrelin system may not only engage antidepressant-like and anxiolytic behaviors that help motivate hungry, prey-susceptible individuals, but also help minimize the development of any related self-destructive behaviors. Daily administration of GGA for 10 days significantly reduced ghrelin mRNA levels in gastric mucosa without changing daily food intake and body weight gain. When the GGA-treated mice were exposed to the repeated restraint stress, the reduction was cancelled and the ghrelin mRNA levels significantly increased to the baseline level. We could not measure plasma ghrelin levels, because there is no reliable antibody for measurement of each modified ghrelin proteins. It has been suggested that the feeding response and body weight changes mediated by ghrelin are likely to be dispensable when food availability is plentiful like our experimental conditions (37). Effects of long-term administration of GGA on ghrelin as well as leptin production and resultant changes in food intake and body weight should be investigated.

We showed that GGA acted as a chaperon inducer on epididymal adipose tissues under stressful condition. However, both leptin and ghrelin levels were significantly affected by a ten-day treatment of GGA (before stress) without significant induction of hspal mRNA and HSP70 protein levels. There is a possibility that the change in leptin and/or ghrelin was caused by not the chaperone but the GGA itself through another signaling pathway.

Unfortunately we did not examine the effects of GGA on anxiety and depression-like behaviors in the present study. At this time point, pathophysiological meaning of the anorexigenic effect of GGA is unknown. Particularly, it is unclear whether GGA-induced decline of food intake in association with the maintenance of circulating leptin levels is advantageous to cope with the psychological stress. However, considering to the effects of leptin and ghrelin on mood, the maintenance of plasma leptin and ghrelin levels may be beneficial for alleviation of anxiety and depressive mood under the stressful situation. Further studies are needed to clarify these issues.

\section{ACKNOWLEDGEMENTS}

This work was supported by the grant from the Takeda Science Foundation (to K.N.) and JSPS KAKENHI Grant Number 16K09314 to K.N.

\section{REFERENCES}

1. Prolo P, Wong M-L, Licinio J : Leptin. Int J Biochem : Cell Biol 30 : 1285-1290, 1998

2. Zhang Y, Proenca R, Maffei M, Barone M, Leopold L, Friedman JM : Positional cloning of the mouse obese gene and its human homologue. Nature $372:$ 425-432, 1994

3. Roubos EW, Dahmen M, Kozicz T, Xu L : Leptin and the hypothalamo-pituitary-adrenal stress axis. Gen Comp Endocrinol $177: 28-36,2012$

4. Margetic S, Gazzola C, Pegg GG, Hill RA : Leptin : a review of its peripheral actions and interactions. Int J Obes 26 : 1407 -
1433, 2002

5. Deck CA, Honeycutt JL, Cheung E, Reynolds HM, Borski RJ : Assessing the functional role of leptin in energy homeostasis and the stress response in vertebrates. Front. Endocrinol. (Lausanne). 8: 63, 2017

6. Haque Z, Akbar N, Yasmin F, Haleem MA, Haleem DJ : Inhibition of immobilization stress-induced anorexia, behavioral deficits, and plasma corticosterone secretion by injected leptin in rats. Stress $16: 353-362,2013$

7. Stieg MR, Sievers C, Farr O, Stalla GK, Mantzoros CS : Leptin : Ahormone linking activation of neuroendocrine axes with neuropathology. Psychoneuroendocrinology $51: 47-57$, 2015

8. Westerheide SD, Morimoto RI : Heat shock response modulators as therapeutic tools for diseases of protein conformation. J Biol Chem 280 : 33097-33100, 2005

9. Sõti C1, Nagy E, Giricz Z, Vígh L, Csermely P, Ferdinandy P : Heat shock proteins as emerging therapeutic targets. $\mathrm{Br} \mathrm{J}$ Pharmacol 146 : 769-780, 2005

10. Hirakawa T, Rokutan K, Nikawa T, Kishi K : Geranylgeranylacetone induces heat shock proteins in cultured guinea pig gastric mucosal cells and rat gastric mucosa. Gastroenterology $111: 345-357,1996$

11. Murakami M, Oketani K, Fujisaki H, Wakabayashi T, Ohgo T: Antiulcer effect of geranylgeranylacetone, a new acyclic polyisoprenoid on experimentally induced gastric and duodenal ulcers in rats. Arzneimittel-Forschung/Drug Res 31 : 799804, 1981

12. Fudaba Y, Tashiro H, Miyata Y, Ohdan H, Yamamoto H, Shibata S, Nishihara M, Asahara T, Fukuda Y, Goto A, Ito H, Dohi K : Oral administration of geranylgeranylacetone protects rat livers from warm ischemic injury. Transplant Proc $31: 2918-2919,1999$

13. Uchida S, Fujiki M, Nagai Y, Abe T, Kobayashi H : Geranylgeranylacetone, a noninvasive heat shock protein inducer, induces protein kinase $\mathrm{C}$ and leads to neuroprotection against cerebral infarction in rats. Neurosci Lett 396 : 220-224, 2006

14. Hashikawa N, Utaka Y, Ogawa T, Tanoue R, Morita Y, Yamamoto S, Yamaguchi S, Kayano M, Zamami Y, HashikawaHobara N : HSP105 prevents depression-like behavior by increasing hippocampal brain-derived neurotrophic factor levels in mice. Sci Adv 3 : e1603014, 2017

15. Adachi H, Kondo T, Ogawa R, Sasaki K, Morino-Koga S, Sakakida M, Kawashima J, Motoshima H, Furukawa N, Tsuruzoe K, Miyamura N, Kai H, Araki E : An acylic polyisoprenoid derivative, geranylgeranylacetone protects against visceral adiposity and insulin resistance in high-fat-fed mice. Am J Physiol Endocrinol Metab 299 : E764-E771, 2010

16. Tanaka K, Tsutsumi S, Arai Y, Hoshino T, Suzuki K, Takaki E, Ito T, Takeuchi K, Nakai A, Mizushima T : Genetic evidence for a protective role of heat shock factor 1 against irritantinduced gastric lesions. Mol Pharmacol 71 : 985-993, 2007

17. Hoshino T, Suzuki K, Matsushima T, Yamakawa N, Suzuki T, Mizushima T: Suppression of Alzheimer's disease-related phenotypes by geranylgeranylacetone in mice. PLoS One $8: \mathrm{e}$ 76306, 2013

18. de Groote L, Peñalva RG, Flachskamm C, Reul JM, Linthorst $\mathrm{AC}$ : Differential monoaminergic, neuroendocrine and behavioural responses after central administration of corticotropin-releasing factor receptor type 1 and type 2 agonists. J Neurochem $94:$ 45-56, 2005

19. Tanaka C, Asakawa A, Ushikai M, Sakoguchi T, Amitani H, Terashi M, Cheng K, Chaolu H, Nakamura N, Inui A: Comparison of the anorexigenic activity of CRF family peptides. Biochem Biophys Res Commun 390 : 887-891, 2009

20. Tempel DL, Leibowitz SF : Glucocorticoid receptors in PVN : 
interactions with NE, NPY, and Gal in relation to feeding. Am J Physiol 265 : E794-E800, 1993

21. Strack AM, Horsley CJ, Sebastian RJ, Akana SF, Dallman MF : Glucocorticoids and insulin : complex interaction on brown adipose tissue. Am J Physiol 268 : R1209-R1216, 1995

22. Khan SM, Hamnvik OPR, Brinkoetter M, Mantzoros CS : Leptin as a modulator of neuroendocrine function in humans. Yonsei Med. J. $53: 671-679,2012$

23. Lu X-Y, Kim CS, Frazer A, Zhang W : Leptin : A potential novel antidepressant. Proc Natl Acad Sci USA 103 : 1593-1598, 2006

24. Miller GE, Freedland KE, Carney RM, Stetler CA, Banks WA : Pathways linking depression, adiposity, and inflammatory markers in healthy young adults. Brain Behav Immun 17 : 276285,2003

25. Lu XY : The leptin hypothesis of depression : a potential link between mood disorders and obesity? Curr Opin Pharmacol $7: 648-652,2007$

26. Rubin RT, Rhodes ME, Czambel RK : Sexual diergism of baseline plasma leptin and leptin suppression by arginine vasopressin in major depressives and matched controls. Psychiatry Res 113 : 255-268, 2002

27. Lawson EA, Miller KK, Blum JI, Meenaghan E, Misra M, Eddy KT, Herzog DB, Klibanski A : Leptin levels are associated with decreased depressive symptoms in women across the weight spectrum, independent of body fat. Clin Endocrinol (Oxf) $76: 520-525,2012$

28. Kojima M, Hosoda H, Date Y, Nakazato M, Matsuo H, Kangawa $\mathrm{K}$ : Ghrelin is a growth-hormone-releasing acylated peptide from stomach. Nature $402: 656-660,1999$

29. Kamegai J, Tamura H, Shimizu T, Ishii S, Sugihara H, Wakabayashi I : Central effect of ghrelin, an endogenous growth hormone secretagogue, on hypothalamic peptide gene expression. Endocrinology $141:$ :797-4800, 2000

30. Nakazato M, Murakami N, Date Y, Kojima M, Matsuo H,
Kangawa K, Matsukura S : A role for ghrelin in the central regulation of feeding. Nature $409: 194-198,2001$

31. Tschop M, Smiley DL, Heiman ML : Ghrelin induces adiposity in rodents. Nature $407: 908-913,2000$

32. Müller TD, Nogueiras R, Andermann ML, Andrews ZB, Anker SD, Argente J, Batterham RL, Benoit SC, Bowers CY, Broglio F, Casanueva FF, D’Alessio D, Depoortere I, Geliebter A, Ghigo E, Cole PA, Cowley M, Cummings DE, Dagher A, Diano S, Dickson SL, Diéguez C, Granata R, Grill HJ, Grove K, Habegger KM, Heppner K, Heiman ML, Holsen L, Holst B, Inui A, Jansson JO, Kirchner H, Korbonits M, Laferrère B, LeRoux CW, Lopez M, Morin S, Nakazato M, Nass R, Perez-Tilve D, Pfluger PT, Schwartz TW, Seeley RJ, Sleeman M, Sun Y, Sussel L, Tong J, Thorner MO, van der Lely AJ, van der Ploeg LH, Zigman JM, Kojima M, Kangawa K, Smith RG, Horvath T, Tschöp MH : Ghrelin. Mol Metab 4 : 437-460, 2015

33. Cummings DE, Weigle DS, Frayo RS, Breen PA, Ma MK, Dellinger EP, Purnell JQ : Plasma ghrelin levels after dietinduced weight loss or gastric bypass surgery. Nutr Clin Metab $16: 219-220,2002$

34. Patterson ZR, Khazall R, MacKay H, Anisman H, Abizaid A : Central ghrelin signaling mediates the metabolic response of C57BL/ 6 male mice to chronic social defeat stress. Endocrinology 154 : 1080-1091, 2013

35. Raspopow K, Abizaid A, Matheson K, Anisman H : Psychosocial stressor effects on cortisol and ghrelin in emotional and nonemotional eaters : Influence of anger and shame. Horm Behav 58: 677-684, 2010

36. Chuang JC, Perello M, Sakata I, Osborne-Lawrence S, Savitt JM, Lutter M, Zigman JM : Ghrelin mediates stress-induced food-reward behavior in mice. J Clin Invest 121 : 2684-2692, 2011

37. Mani BK, Zigman JM : Ghrelin as a Survival Hormone. Trends Endocrinol Metab 28 : 843-854, 2017 